\title{
Perceptions on service quality: A study of old age homes in Kerala and Tamil Nadu
}

\author{
Devika Anil, and K Hemamala \\ Amrita School of Business, Amrita VishwaVidyapeetham, Coimbatore, India \\ devikaa.feb09@gmail.com
}

\begin{abstract}
The proportion of old age citizens (above 60 years) in India constitutes $8.6 \%$ of the total population ( 60 million). $1 \%$ of this population currently resides in old age homes across India due to various reasons. The present living conditions of elderly in old age homes are not commendable. It has been found from research that the setting of old age homes and the employees influence the welfare of the residents and their health care. Despite various services provided, researchers have concluded that service gaps exist among staff and residents of old age homes. In the present scenario, it is the need of the hour to understand the living standards of the older generation in old age homes, to study the various services offered by them and how the residents spend their lives there in order to better their conditions of living. The purpose of this paper is (i) to draw insights from an in-depth analysis of old age homes and (ii) to study the perceptions in service quality of old age homes; by studying old age homes in the Indian states of Kerala and Tamil Nadu. Data for the study was collected through a face to face interview with its residents. Analysis of the collected data shows that 'responsiveness' and 'empathy' are the dimensions that are to be improved in both the states to increase overall satisfaction levels and meet the expectations of residents. The quality of the attributes, 'Cleaning services for rooms', 'freedom to plan own time' and 'respect for residents' privacy' shall be improved by old age homes in order to improve the perception of service quality by residents.
\end{abstract}

\section{INTRODUCTION}

India, being the second most populated country in the world, is home to about 1.32 billion people. About $8.6 \%$ (60 million) of the population constitutes people above the age of 60 (senior citizens). Advanced medical care, spread of modern medicine and hence falling mortality rates will lead to a rapid increase in elderly population in the years to come. It is estimated that the current elderly population of 60 million is projected to exceed 227 million by 2050 (an increase of nearly $280 \%$ ) [1].

After retirement, many of them face humiliation and are forced to live their life at the mercy of their children and relatives. Many of them are also victims of physical as well as mental ailments, are bedridden and have limited mobility. Old age means reduced physical ability, declining mental ability, the gradual giving up of role playing in socio-economic activities, and a shift in economic status moving from economic independence to economic dependence upon other's for support [2]. They fall into a state of solitude especially when their partner passes away. These reasons are enough to exploit their life and force them to live a life of abuse and isolation or abandon them in old age homes. The number of old age homes has increased a lot in the recent years due to various societal and cultural changes [1]. This shows that more than half of the population of elderly spends their last phase of life until death in old age homes. Therefore it is important to understand how they live their life in old age homes, the facilities offered and the level of satisfaction they have.

The paper is structured as follows. The research gap is identified with the help of literature review. Later it focuses on the methodology of this study, the analysis and finally the results are discussed.

\section{LITERATURE REVIEW}

\section{A. Elderly in India}

Citizens of India above the age of 60 are considered as elderly or senior citizens. They constitute the old age population of India - about $8.6 \%$ of the total population [3]. The proportion of elderly is highest in Kerala followed by Tamil Nadu. The elderly constitutes $12.6 \%$ of the population in Kerala and $10.4 \%$ in Tamil Nadu. The rate of increase in aged population is also high in Kerala followed by Tamil Nadu [3].

People with higher life satisfaction describe themselves as having social supports in a more extensive, frequent, and reliable ways, a more contented feeling in their relationships with others, and engaging in a greater number of pleasant activities as well. They are reported to have fewer irrational beliefs, were more optimistic and less pessimistic, and had lower levels of reported cognitive difficulty [4]. But the living conditions of elderly are degrading now-a-days with very low life satisfaction rates. About 15 million of this population leads a lonely and secluded life due to various reasons like abuse from home, death of partner, 
chronic ailments etc. The dependency rates of elderly on others is high in Kerala (19.6\%) followed by Tamil Nadu (15.8\%). The proportion of people who owns any asset in India is high in Kerala and very low in Tamil Nadu. A little over $18 \%$ of elderly are receiving pension in Kerala while this rate is only $4 \%$ in Tamil Nadu [5]. A large proportion of people do not own any asset, are not eligible for pension and are highly dependent on children and other relatives. These statistics show that older people in India, especially in Kerala and Tamil Nadu, are not satisfied with their living conditions.

\section{B. Emerging sector of old age homes in India}

An old age home is generally defined as a home for old people who have no one to look after them or those who have been thrown out of their homes by their children. Old age homes in India are managed by individuals (private) with diverse professional and disciplinary background, religious institutions and government organizations without any age-specific qualifications. Most of them operate as charity (free) though there are some profit oriented (paid) homes as well [1].

The number of old age homes has increased a lot in the recent years due to various social, economic, cultural and demographic changes. Urbanization, modernization and globalization have led to changes in the economic structure like migration to large cities and other countries for better opportunities, the erosion of societal values, lack of attachment between children and parents, weakening of social values, relationships, and social institutions such as the joint family [1]. This reduces the availability of care in homes and are forced to move into old age homes. Problems with children like abuse, misbehaviour by son and daughter-in-law and life threats from them, having no children, lack of care at home since children are away, adjustment issues, loneliness at home, chronic ailments and own preference are the major reasons to choose old age home [6].

The state of Kerala serves the largest number of old age homes in India followed by Tamil Nadu and Goa [7]. The proportion of people living in old age homes has increased a lot in the recent years. A $69 \%$ increase in number of residents of old age homes has been reported in Kerala alone in the last four years. The proportion of females living in old age homes is more than $50 \%$, compared to men. The average age group of elderly living in old age homes is 70-80. The elderly who choose to live in old age homes include people who earn an income through pension, those who are fully dependent on others and a very small population who are still employed.

\section{Service quality dimensions and service gap}

Service quality is the difference between customer expectations of service and perceived service (Parasuraman et al., 1985; Lewis et al., 1990). The five dimensions of service quality are reliability, responsiveness, assurance, empathy and tangibles. All the basic facilities and services from any service provider can be categorized into these five dimensions developed by Parasuraman et al in their studies $(1985 ; 1988 ; 1991 ; 1994)$. It is used to measure the quality of service, satisfaction level of customers and identify service gap, if any. This method along with SERVQUAL model (Gronroos, 1982; Lewis et al., 1983; Parasuraman et al., 1985) has been successfully used to measure customer satisfaction in service sectors like banks [8], hospitals [9], education [10], e-service [11], ports [12] etc. All these sectors provide basic services like visually appealing facilities consistent with the industry, up to date equipment and well-dressed employees (tangibles), responding within time frame to customers, dependability and efficient service delivery (reliability), polite and trustworthy employees and safe transactions (assurance), prompt service from employees and readiness and willingness of employees to help (responsiveness) and providing individualized attention and understanding customer needs (empathy) [ 13].

Care giving facilities like nursing homes, palliative care and hospitals have used this method to understand service gap and measure customer satisfaction levels. This has also been used by certain retirement homes in Hong Kong and Japan to measure the same.

\section{Perceived service and service gap in old age homes}

Studies have shown that the influence of the setting and the role of the staff in old age care are very important to make them happy, contented and healthy. Among depicted services and facilities in old age homes, residents rated the quality and behaviour of old age home staff as most important, whereas the choice of food and mealtimes were rated the least important. [14]. Care staff being able to spend enough time with residents, feeling at home in shared spaces, and staff being very flexible in care routines are the characteristics identified as important for residents. Satisfaction with the privacy in the living environment is one of the most important determinants of life satisfaction [15].

Though old age homes provide good services to their residents, considerable knowledge and service gaps exist among staff and residents of old age homes [15]. 
In the present scenario, it is important to study the various services offered by old age homes in India and how the residents spend their lives there to understand where improvements have to be made. Researches clearly show that service gaps do exist in services provided by old age homes. But the study on differences in expectation and perception of service quality and their areas of occurrence has not has not been done very extensively in India. Apparently no studies have been conducted in this regard about old age homes especially in the Indian states of Kerala and Tamil Nadu, where largest number of old age homes operate in the country. Therefore this paper aims to (i) to draw insights from an in-depth analysis of old age homes and (ii) to study the perceptions in service quality of old age homes; by studying old age homes in Kerala and Tamil Nadu.

\section{METHODOLOGY}

\section{A. Data description}

For the purpose of this study, data was collected from a sample of 120 residents of different age, gender and social status, across various old age homes in Kerala and Tamil Nadu. Face to face interview was conducted to collect data from elderly in old age homes. The following table describe a portion of data collected for this study.

\section{TABLE 1: A SAMPLE DATA}

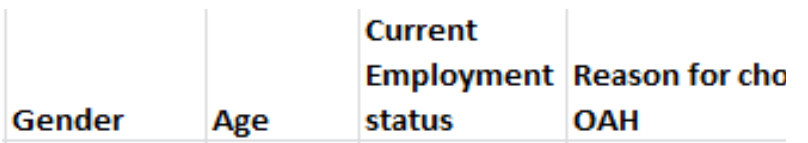

\begin{tabular}{|l|l|l|}
\hline Male & & \\
\hline Female & 78 Voluntary & Own preferen \\
\hline Male & 70 Unemployed & Problems with \\
\hline Male & 68 Unemployed & Problems with \\
\hline Female & 72 Retired & Problems with \\
\hline Female & 74 Unemployed & No one at hom \\
\hline Male & 80 Unemployed & No one at hom \\
\hline Male & 71 Retired & Own preferen \\
\hline Female & 73 Retired & No one at hom \\
\hline
\end{tabular}

\section{B. Questionnaire development}

The various services provided by the old age homes to the residents are identified [13]. They are then classified as different attributes under five service dimensions as follows:

\section{TABLE 2: SERVICE DIMENSIONS AND} ATTRIBUTES

\begin{tabular}{|c|c|}
\hline Service dimensions & Attributes \\
\hline \multirow{3}{*}{ Reliability } & Appropriate medical care \\
\hline & Specialized medical care \\
\hline & Food and medicines on time \\
\hline \multirow{2}{*}{ Responsiveness } & Choice of food \\
\hline & Vehicle for emergency \\
\hline \multirow{4}{*}{ Assurance } & Feel safe \\
\hline & Feel a sense of family \\
\hline & Management ask for your feedback \\
\hline & Behaviour of staff \\
\hline \multirow{7}{*}{ Empathy } & Individualized attention \\
\hline & Freedom to plan your time \\
\hline & Freedom to go in and out \\
\hline & Freedom to express your opinions \\
\hline & Sessions on meditation, yoga etc \\
\hline & Games or entertainment sessions \\
\hline & Their respect for your privacy \\
\hline \multirow{2}{*}{ Tangibles } & Calm and quiet atmosphere \\
\hline & Clean rooms \\
\hline
\end{tabular}

The questions were asked to the residents to collect data on various attributes of service quality dimensions of old age homes. The same set of questions was asked to management to understand their perception on the quality of services they provide. The attributes were measured using a 3 point (Milte R et al., 2017) and 5 point Likert scale ranging from "Strongly Agree" to "Strongly Disagree" (Bearden et al., 1993). Also, there were questions developed to understand the demographics and background of the respondents - age, gender, current employment status and reasons for choosing old age home.

\section{Analysis method}

Weighted average method is used for plotting the graph between (i) perception of attributes of old age homes in Kerala and Tamil Nadu, (ii) perception on quality of attributes by residents and perception on its delivery by management for both Kerala and Tamil Nadu and to compute variation. Weights are assigned to each point in scale and the average value of an attribute by all the residents is calculated. 


\section{RESULTS, DISCUSSION AND FUTURE RESEARCH \\ A. Insights on data collected from old age homes (Kerala and Tamil Nadu)}

\section{TABLE 3: DEMOGRAPHIC CHARACTERISTICS OF RESPONDENTS}

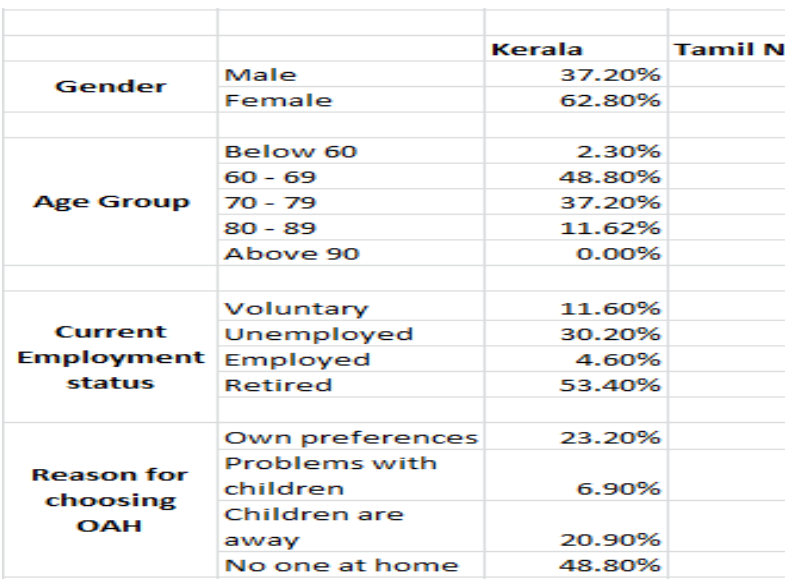

The above given table shows the percentage of respondents belonging to different gender, age groups, current employment status and reason for staying in old age homes. The highest percentage is shown in the age group $60-69(48.8 \%)$ in Kerala. Response from residents shows that about $15-20 \%$ elderly in Kerala choose life in old age homes immediately after they retire to lead a peaceful endof-life with people of same age group, when one of the partners is no more or since children are far away. Responses show that only a small percentage of them have issues with their children. $53 \%$ of the respondents are leading a retired life. In Tamil Nadu, $67.4 \%$ belong to the age group $70-79$.

Only less than $50 \%$ of them leave their homes since there is no one at home. Compared to Kerala, a good percentage of respondents face humiliation and abuse due to issues with their own children, in Tamil Nadu. More than half of them are unemployed as well. They are either send to old age homes and are paid for their expenses by children and relatives or are abandoned in charity homes where they have to live a life at the mercy of others.

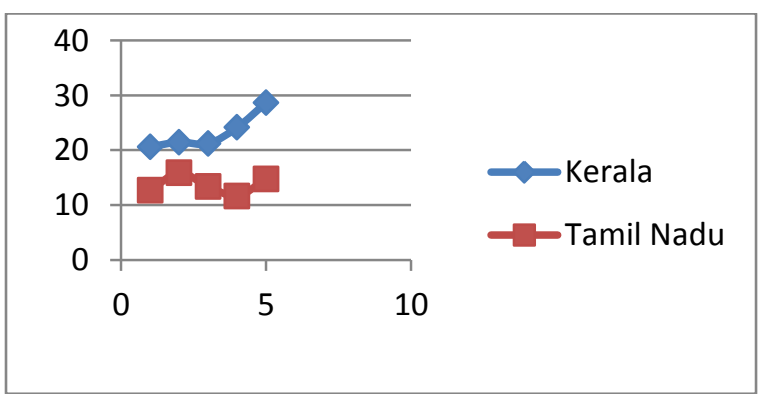

FIGURE 1: WEIGHTED AVERAGE VALUES FOR SERVICES
TABLE 4: WEIGHTED AVERAGE VALUES OF SERVICES

\begin{tabular}{r|l|r|r|r|} 
No. & \multicolumn{1}{|c|}{ Dimensions } & Kerala & Tamil Nadu & $\begin{array}{c}\text { Gap } \\
\text { (Variation) }\end{array}$ \\
\hline 1 & Reliability & 20.63 & 12.67 & 7.96 \\
\hline 2 & Responsiveness & 21.45 & 15.87 & 5.57 \\
\hline 3 & Assurance & 21.2 & 13.37 & 7.82 \\
\hline 4 & Empathy & 24.15 & 11.67 & 12.47 \\
\hline 5 & Tangibles & 28.68 & 14.75 & 13.9 \\
\hline & & & & \\
\hline
\end{tabular}

The above given graph compares the old age homes in Kerala and Tamil Nadu in terms of the weighted average values (Y-axis) for the service dimensions.

Reliability has shown lowest values among others, in Kerala because of the lowest value of attribute 'specialized medical care'. Assurance and responsiveness shows the next lowest value due to the low value of the attribute 'feeling of safety' and 'vehicle for emergency' respectively. 'Cleaning services for rooms', 'freedom to plan own time and to move in and out' and 'respect for residents' privacy' are the other attributes that have shown low values. They are allowed to move in and out as they wish, but certain rules are kept such as timing to go out and letting the authorities know about their movement.

Empathy has shown the lowest value in Tamil Nadu because of the lowest values of 'freedom to move in and out' and 'respect for residents' privacy'. 'Cleaning services for rooms', 'freedom to plan own time' and 'respect for residents' privacy' are the other attributes that have shown low values. Compared to Kerala, the average age of residents in old age homes of Tamil Nadu is high. Therefore special care is given for their welfare and the staffs are always watchful of them. Hence they are not allowed to do all of the everyday activities as they wish.

The low value for certain attributes, mentioned above, in both states shows that there are homes where the elderly have to live a scheduled life. This keeps a check on the residents' safety since they are unhealthy and are leading their last phase of life, though few of them complain about it being a prisoned life.

Another important observation is that some of the elderly become emotionally shattered and fall into geriatric depression (depression which affects elderly) due to these rules and feel themselves to be a burden for others especially those who were forced to live in old age homes by their relatives. Old age homes organize prayer sessions, sessions on yoga, meditation; counselling, small exercise sessions to keep them engaged and not let them victims of 
geriatric depression. Some people enjoy them whereas others feel that the management is breaking the wall of privacy for them. Such people are reluctant to speak and engage with fellow inmates and visitors. They are given mental support through sessions of counselling.

Tangibles have shown the highest value in Kerala due to the high value of the attribute 'calm and quiet atmosphere'. Responsiveness has shown highest value in Tamil Nadu due to the high value of the attribute 'vehicle for emergency'. 'Games and entertainment sessions, sessions on yoga, meditation and counselling and choice of food are the other attributes that have shown high values in both the states. Choice of food is also a prominent service for residents in Tamil Nadu.

The highest variation among the dimensions is found in 'Tangibles' due to considerable differences in values of attributes such as "calm and quiet atmosphere' and 'clean rooms' and the way they are delivered in Kerala and Tamil Nadu. 'Sessions on meditation, yoga etc.', 'games and other entertainment sessions and 'individualized attention' show considerable variation indicating that the same services are being delivered in different ways to two different population who have common interests. This results in different levels of satisfaction for residents in Kerala and Tamil Nadu, where Kerala shows an upper hand in service delivery and overall satisfaction.

\section{B. Perceptions on quality of service provided}

FIGURE 2: AVERAGE VALUES OF SERVICES FOR KERALA

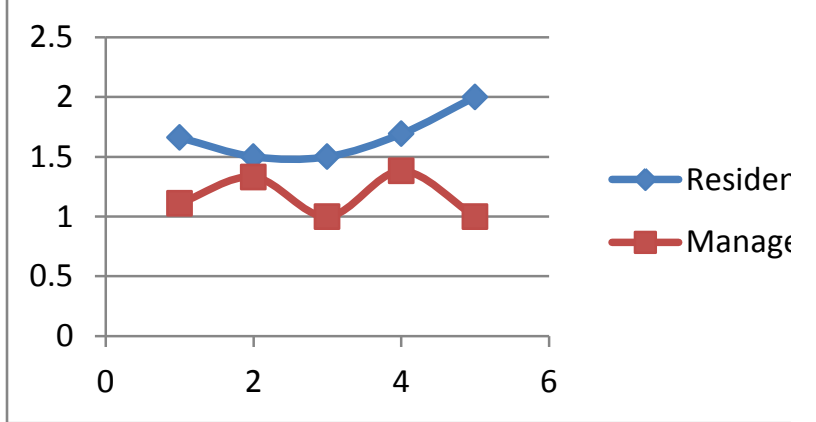

TABLE 5: AVERAGE VALUES OF SERVICES FOR KERALA

\begin{tabular}{|r|l|r|r|r|}
\hline No. & Dimensions & Residents & Management & $\begin{array}{c}\text { Gap } \\
\text { (Variation) }\end{array}$ \\
\hline 1 & Reliability & 1.66 & 1.11 & 0.55 \\
\hline 2 & Responsiveness & 1.5 & 1.33 & 0.16 \\
\hline 3 & Assurance & 1.5 & 1 & 0.5 \\
\hline 4 & Empathy & 1.69 & 1.38 & 0.31 \\
\hline 5 & Tangibles & 2 & 1 & 1 \\
\hline
\end{tabular}

FIGURE 3: AVERAGE VALUES OF SERVICES FOR TAMIL NADU

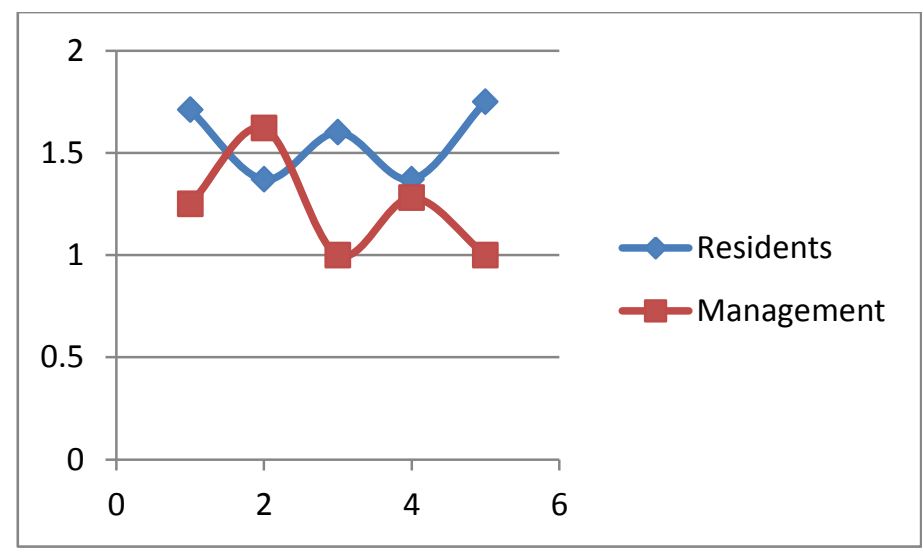

TABLE 4: AVERAGE VALUES OF SERVICES FOR TAMIL NADU

\begin{tabular}{|r|l|r|r|r|}
\hline No. & Dimensions & Residents & Management & $\begin{array}{c}\text { Gap } \\
\text { (Variation) }\end{array}$ \\
\hline 1 & Reliability & 1.71 & 1.25 & 0.46 \\
\hline 2 & Responsiveness & 1.37 & 1.62 & -0.25 \\
\hline 3 & Assurance & 1.6 & 1 & 0.6 \\
\hline 4 & Empathy & 1.37 & 1.28 & 0.08 \\
\hline 5 & Tangibles & 1.75 & 1 & 0.75 \\
\hline
\end{tabular}

The graphs show the average values of responses received from both residents and management of various old age homes.

The graph of Kerala shows that the perception of quality of service is either equivalent or more than what the management provides at present. The variation in values among residents and management is highest for tangibles since it includes the attribute 'calm and quiet atmosphere' which has a high value. 'Freedom to express opinions and feedbacks' and 'timely availability of food and medicines' and 'games and other entertainment sessions' are other attributes which shows high variation in values indicating that residents are highly satisfied regarding these services. The variation is lowest for 'rooms getting cleaned', 'freedom to plan own time', 
'freedom to move in and out' and 'respect for residents' privacy'.

The graph of Tamil Nadu also shows that the perception of quality of service is either equivalent or more than what the management provides at present except responsiveness since it includes a low valued attribute 'games and entertainment sessions'. The residents long for such sessions since they can bring out a sense of feeling like a family and increase the bonding among them. But many old age homes are reluctant to conduct such sessions on a regular basis though they conduct very few of them. The variation in values for the service among residents and management is highest for 'freedom to express opinions and feedbacks' and 'timely availability of food and medicines', indicating that residents are highly satisfied regarding the quality of these services. The variation is lowest for 'rooms getting cleaned', 'freedom to plan own time', 'freedom to move in and out', ' respect for residents' privacy', 'sessions on meditation, yoga etc.', and 'individualized attention'. This indicates that the management shall focus more on improving the standards of delivering these services in order to maintain or increase the satisfaction of residents. The management shall also make efforts to conduct entertainment sessions to provide them with the happiness,fun and satisfaction they long for, thereby making the variation in value positive.

\section{CONCLUSION}

The observations are almost similar for the two states except for a few attributes. Those that bear the highest and lowest differences in both states are almost the same indicating that delivery and perception of service are similar in almost all old age homes, irrespective of location of old age homes and age and gender of the residents. The satisfaction levels are high since most of the old age homes have facilities that are important for delivering services efficiently, such as an ambulance facility for emergency, a duty doctor at a phone call away and periodical meetings to discuss the problems and issues of residents, if any. Response shows that elderly are satisfied if they feel that there is someone who can communicate with them every day with love and care and attend to them when need arises. On the other hand, there are few services that the residents feel, should be improved. This happens because some old age homes give importance to a set of services and fail to provide others well. Some other homes impose certain rules for the well-being of their residents but residents feel highly dissatisfied at these services. This results in a huge variation in satisfaction levels. The management shall focus more on improving the standards of delivering these services in order to maintain or increase the satisfaction of residents.

\section{LIMITATIONS AND FUTURE SCOPE}

Data collected for analysis was majorly from cities of both states. The future studies can focus on old age homes from other areas as well to avoid cultural changes. It can give better insights into the services offered in old age homes and find differences in its operations within a state, if any.

\section{REFERENCES}

[1] Johnson et al.. (2017). A Qualitative Analysis of the Emergence of Long Term Care (Old Age Home) Sector for Seniors Care in India: Urgent Call for Quality and Care Standards. Ageing Int, 17(93).

[2] Rajan, S.I \& Mishra, U.S. (2001). Health concerns among India's elderly. INT'L $J$ Aging and Development, 53(3), 181-194.

[3] Government of India. Ministry of Statistics and Programme Implementation (2016). Elderly in India - Profile and programmes 2016. India.

[4] Lewinsohn, P.M. Redner, J.E., \& Seeley, J.R. (1988). In F. Strack, M. Argyle, \& N. Schwarz (Eds.), Subjective well-being. Oxford, England: Pergamon Press.

[5] United Nations Population Fund (UNFPA 2014).

The Status of Elderly in Tamil Nadu 2011. India

[6] Kumari, S, Verma, M \& Gupta, S. (2016). International Journal of Applied and Pure Science and Agriculture (IJAPSA), 2(5).

[7] Thehinducom. (2018). The Hindu. Retrieved 19 March,

2018, fromhttp://www.thehindu.com/news/cities/Thir uvananthapuram/oldage-homes-reflect-sorry-

statistics/article7670066.ece

[8] Fragoso, J.T \& Espinoza, I.L. (2017). SERVPERF Contaduría y Administración , 62, 1270-1293.

[9] Al-momani, M.M. (2015). Gap Analysis between Perceptions and Expectations of Medical-Surgical Patients in a Public Hospital in Saudi Arabia. Department of Community Health Sciences, College of Applied Medical Sciences, King Saud University, Riyadh, Kingdom of Saudi Arabia, 25, 79-84.

[10] Abari, A.A.F, Yarmohammadian, M.H \& Esteki, M. (2011). Procedia Social and Behavioral Sciences, 15, 2299-2304.

[11] Barrera, R.B. et al., (2014). Revista Europea de Dirección y Economía de la Empresa, 23(M31).

[12] Yeo, G.T, Thai, V.V \& Roh, S.Y. (2015). An Analysis of Port Service Quality and Customer Satisfaction: The Case of Korean Container Ports, 31(4).

[13] Niebuur, J. (2014). Network for studies on Pension, Age and Retirement.

[14] Hawton, A., et.al (2012). Journal of Integrated care, 20(3), 181-194. 
[15] Lee, J.E.N.N.Y., et.al (2013). JOURNAL OF PALLIATIVE MEDICINE, 16(10), 1268-1274.

[16] Niebuur, J. (2014). Network for studies on Pension, Age and Retirement.

[17] HelpAge India. (2015). The State of Elderly in India Report 2011. India.

[18] OECD/European Commission (2013), A Good Life in Old Age? Monitoring and Improving Quality in Long-term Care, OECD Health Policy Studies, OECD Publishing.

[19] Choudhary, A. (2013). International Journal of Science and Research (IJSR), 4(9).

[20] Suresh, M \& Mohan, D. (2016). IEEE International Conference on Computational Intelligence and Computing Research, ICCIC 2015.

[21] Suar, D, Mishra, S \& Khuntia, R. (2007). Asian Journal of Social Psychology, 10(2), 117-122.

[22] Mahalingam, S, Jain, B \& Sahay, M. (2016). 16 International Conference on Advances in Computing, Communications and Informatics, ICACCI, 10691072. 